\title{
Structure, toxicity and antibiotic activity of gramicidin $S$ and derivatives
}

\author{
J. Swierstra ${ }^{1}$ - V. Kapoerchan ${ }^{2}$ A. Knijnenburg ${ }^{2}$ - A. van Belkum ${ }^{1,3} \cdot$ M. Overhand ${ }^{2}$
}

Received: 21 January 2016 / Accepted: 21 January 2016 / Published online: 17 February 2016

(C) The Author(s) 2016. This article is published with open access at Springerlink.com

\begin{abstract}
Development of new antibiotics is declining whereas antibiotic resistance is rising, heralding a postantibiotic era. Antimicrobial peptides such as gramicidin S (GS), exclusively topically used due to its hemolytic side-effect, could still be interesting as therapeutic compounds. By modifying the amino-acid composition of GS, we synthesized GS analogues. We now show that derivative VK7 has a lower MIC $(7.8-31.2 \mu \mathrm{g} / \mathrm{ml}$, median $15.6 \mu \mathrm{g} / \mathrm{ml}$ ) against strains of multi-drug resistant (MDR) Klebsiella pneumoniae, Acinetobacter baumannii, and Pseudomonas aeruginosa than GS has (3.9-62.5 $\mu \mathrm{g} / \mathrm{ml}$, median $31.3 \mu \mathrm{g} / \mathrm{ml}$ ). Low MICs for both VK7 and GS were observed for Staphylococcus aureus and Enterococcus faecium. VK7 showed reduced haemolysis and less lactate dehydrogenase release. All compounds were fully bactericidal at MIC values. Modification of GS enables production of novel derivatives potentially useful for systemic treatment of human infections.
\end{abstract}

J. Swierstra

jasperswierstra@gmail.com

1 Department of Medical Microbiology and Infectious Diseases, Erasmus University Medical Centre, 's Gravendijkwal 230, 3015 CE Rotterdam, The Netherlands

2 Faculty of Science, Bio-Organic Synthesis, Gorlaeus Laboratories, Leiden Institute of Chemistry, Einsteinweg 55, 2333 CC Leiden, The Netherlands

3 bioMérieux, R\&D Microbiology, 3 Route de Port Michaud, La Balme-Les-Grottes 38390, France

\section{Introduction}

Six bacterial pathogens with a propensity for developing multi-drug resistance (MDR) are specifically warned for by the Infectious Disease Society of America (IDSA) (ESKAPE: Enterococcus faecium, Staphylococcus aureus, Klebsiella pneumoniae, Acinetobacter baumannii, Pseudomonas aeruginosa, and extended spectrum beta lactamase (ESBL)producing Enterobacteriaceae). These species are causing the majority of human infections and efficiently acquire additional resistance traits [1], which implies that new antibiotics have to be effective against these actively evolving MDR pathogens. The incidence of vancomycin-resistant Enterococci (VREs) has increased dramatically over recent years [2]. S. aureus, especially methicillin-resistant $S$. aureus (MRSA), currently causes more deaths in the USA annually than HIV and tuberculosis combined [2]. ESBLs continue to be on the rise and limit treatment options [3]. P. aeruginosa is becoming increasingly resistant to multiple classes of drugs [4], whereas Acinetobacters are naturally resistant to many classes of antibiotics [5]. Increasing antibiotic resistance leads to extended hospitalization, rising treatment costs, and increased morbidity and mortality.

The rise of antibiotic-resistant pathogens has sparked research into currently disregarded antimicrobial peptides including gramicidin S (GS). GS is naturally produced by Aneurinibacillus migulanus [6] and was first discovered in 1941 [7]. GS shows antimicrobial activity against both Gram-positives and Gram-negatives in a MIC range from 4$64 \mu \mathrm{g} / \mathrm{ml}$ [8]. The lowest MICs are seen for Gram-positive bacterial species [9]. Despite its good antimicrobial activity, GS cannot be used systemically due to its haemolytic sideeffect [10] and is therefore only applied topically to treat superficial infections [11]. GS is a cyclic, C2-symmetrical decapeptide with the sequence cyclo(Pro- ${ }^{\mathrm{D}} \mathrm{Phe}-\mathrm{Leu}-\mathrm{Orn}-$ 
Val) 2 . The two Pro- ${ }^{\mathrm{D}}$ Phe dipeptides form two type II $\beta$-turns, and the two Leu-Orn-Val stretches form an antiparallel $\beta$ sheet. GS has been reported to kill bacteria by forming pores in the outer membranes [8]. Native GS is a natural scaffold for amino acid alteration in such a way that antimicrobial activity is retained but toxicity is reduced. In previous attempts to modify GS, several strategies have been followed: nonnatural amino-acids were included [12], the size of the ring has been modified [8], and the $\beta$-turn region [13] and $\beta$-strand region have been changed [14]. Still, few new derivatives of GS have been identified that show retention of antimicrobial activity with reduced toxicity $[8,15-18]$. We here study the $\beta$ strand-modified GS analogue VK7 [14] and the $\beta$-turn modified derivative 20 [13]. Studying naturally occurring antimicrobial peptides such as GS could help with the design and development of novel derivative drugs to combat multidrug resistance.

\section{Material and methods}

ESKAPE panel collection and characterization Except for the $S$. aureus USA 300 and MRSA 252 strains [19], ESKAPE strains were collected at the Department of Medical Microbiology and Infectious Disease in the Erasmus Medical Centre, Rotterdam, The Netherlands. Thirty clinical isolates of E. faecium (5), S. aureus (5), K. pneumonia (5), A. baumannii (5), P. aeruginosa (5) and E. cloacae (5) were isolated from January 2010 to October 2011 from different wards (Table 1). All strains were cultured on Columbia agar plates with $5 \%$ sheep blood (Becton Dickinson, Breda, The Netherlands) overnight at $37^{\circ} \mathrm{C}$ before antibiotic susceptibility testing. Antibiotic resistance was determined using disk diffusion following Clinical and Laboratory Standards Institute (CLSI) guidelines and VITEK2 (bioMérieux, Zaltbommel, The Netherlands) following manufacturer's protocol; susceptibility was determined using EUCAST breakpoints [20].

MIC determination Antimicrobial activity of GS and derivatives (Fig. 1) was determined following the CLSI guidelines and in triplicate [21]. Briefly, bacterial cells were cultured overnight on Columbia agar plates with $5 \%$ sheep blood (Becton Dickinson, Breda, The Netherlands). Colonies were suspended in $0.9 \%$ $\mathrm{NaCl}$ to a density of $0.5 \mathrm{McF}$ arland, then diluted 1:100 in Müller-Hinton Broth (MHB, Oxoid, Badhoevedorp, The Netherlands); $100 \mu \mathrm{l}$ of this suspension was added to wells containing GS, derivatives 3,20 , or VK7 ranging from a concentration of $0.95 \mu \mathrm{g} / \mathrm{ml}$ to $62.5 \mu \mathrm{g} / \mathrm{ml}$ in MHB. Ninety-six well plates (Greiner Bio One, Alphen aan den Rijn, The Netherlands) were incubated for 18-24 hours at $37^{\circ} \mathrm{C}$, and MIC values were determined visually.
Table 1 Review of clinical isolates, their MICs to GS and derivatives, toxicity levels, and therapeutic indices

\begin{tabular}{|c|c|c|c|c|c|}
\hline & $\begin{array}{l}\text { Strain } \\
\#\end{array}$ & 3 & 20 & GS & $\begin{array}{l}\text { VK- } \\
7\end{array}$ \\
\hline \multirow[t]{5}{*}{ Enterococcus faecium } & 1 & 7.8 & 15.6 & 3.9 & 3.9 \\
\hline & 2 & 7.8 & 15.6 & 3.9 & 3.9 \\
\hline & 3 & 7.8 & 7.8 & 3.9 & 3.9 \\
\hline & 4 & 7.8 & 7.8 & 3.9 & 3.9 \\
\hline & 5 & 7.8 & 3.9 & 3.9 & 3.9 \\
\hline \multirow{5}{*}{$\begin{array}{l}\text { Staphylococcus } \\
\quad \text { aureus }\end{array}$} & 1 & 31.3 & 7.8 & 3.9 & 7.8 \\
\hline & 2 & 7.8 & 3.9 & 3.9 & 3.9 \\
\hline & 3 & 62.5 & 62.5 & 7.8 & 15.6 \\
\hline & 4 & 31.3 & 7.8 & 3.9 & 7.8 \\
\hline & 5 & 31.2 & 7.8 & 3.9 & 7.8 \\
\hline \multirow{5}{*}{$\begin{array}{l}\text { Klebsiella } \\
\quad \text { pneumoniae }\end{array}$} & 1 & 62.5 & 62.5 & 31.3 & 15.6 \\
\hline & 2 & 31.3 & 62.5 & 62.5 & 15.6 \\
\hline & 3 & 62.5 & 62.5 & 62.5 & 15.6 \\
\hline & 4 & 31.3 & 62.5 & 31.3 & 15.6 \\
\hline & 5 & 15.6 & 15.6 & 7.8 & 15.6 \\
\hline \multirow{5}{*}{$\begin{array}{c}\text { Acinetobacter } \\
\text { baumannii }\end{array}$} & 1 & 31.3 & 62.5 & 31.3 & 15.6 \\
\hline & 2 & 31.3 & 62.5 & 62.5 & 7.8 \\
\hline & 3 & 62.5 & 62.5 & 31.3 & 15.6 \\
\hline & 4 & 62.5 & 62.5 & 15.6 & 15.6 \\
\hline & 5 & 31.3 & 62.5 & 62.5 & 31.2 \\
\hline \multirow{5}{*}{$\begin{array}{r}\text { Pseudomonas } \\
\text { aeruginosa }\end{array}$} & 1 & 31.3 & 62.5 & 31.3 & 7.8 \\
\hline & 2 & 31.3 & 31.3 & 31.3 & 7.8 \\
\hline & 3 & 31.3 & 31.3 & 31.3 & 7.8 \\
\hline & 4 & 62.5 & 62.5 & 62.5 & 7.8 \\
\hline & 5 & 62.5 & 62.5 & 62.5 & 7.8 \\
\hline \multirow{5}{*}{$\begin{array}{c}\text { Enterobacter } \\
\text { cloacae }\end{array}$} & 1 & 3.9 & 7.8 & 3.9 & 7.8 \\
\hline & 2 & 3.9 & 7.8 & 7.8 & 15.6 \\
\hline & 3 & 7.8 & 7.8 & 3.9 & 7.8 \\
\hline & 4 & 3.9 & 1.95 & 1.95 & 7.8 \\
\hline & 5 & 62.5 & 62.5 & 62.5 & 15.6 \\
\hline $\begin{array}{l}\text { Toxic dose } 50 \% \\
\text { (hemolyse) }\end{array}$ & & 41.6 & nd & 35.2 & nd \\
\hline $\begin{array}{l}\text { Toxic dose } 50 \% \\
\text { (LDH) }\end{array}$ & & 49.8 & 62.5 & 18.7 & nd \\
\hline MIC lowest values & & 3.9 & 1.95 & 1.95 & 3.9 \\
\hline MIC highest values & & 62.5 & 62.5 & 62.5 & 31.2 \\
\hline $\begin{array}{l}\text { TI following } \\
\text { hemolysis } \\
\text { range }\end{array}$ & & $\begin{array}{l}0.66- \\
10.67\end{array}$ & nd & $\begin{array}{l}0.56- \\
18.05\end{array}$ & nd \\
\hline $\begin{array}{l}\text { TI following LDH } \\
\text { release } \\
\text { range }\end{array}$ & & $\begin{array}{l}0.80- \\
12.77\end{array}$ & $\begin{array}{l}1- \\
32.05\end{array}$ & $0.30-9.9$ & nd \\
\hline
\end{tabular}

Note: nd: not determined since the maximum concentration did not cause toxicity.

To determine whether antimicrobial activity was bactericidal, $200 \mu \mathrm{l}$ of the suspension was plated onto new Columbia agar plates with $5 \%$ sheep blood, and colonies were counted. 

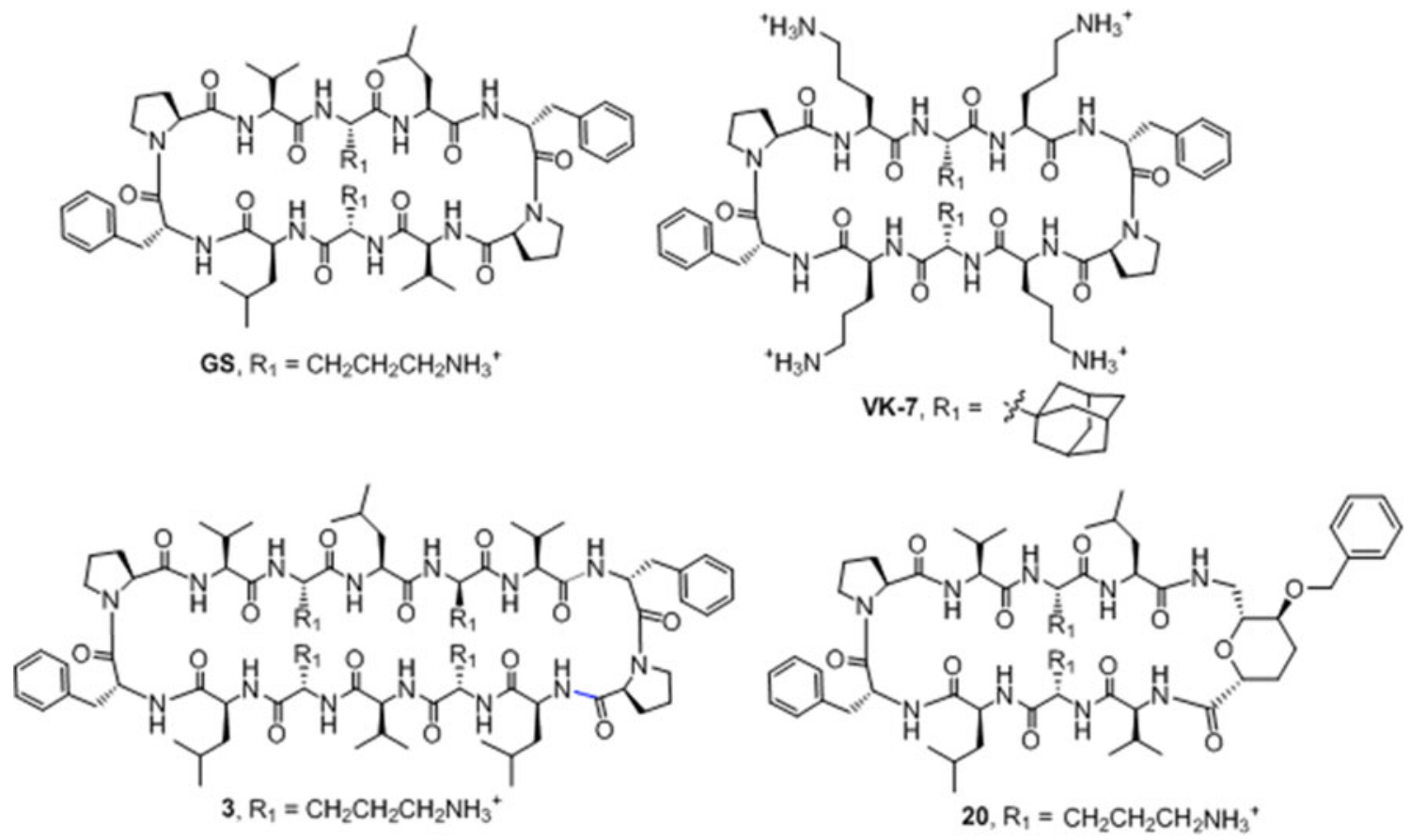

Fig. 1 Structure of GS and the three derivatives studied here

Haemolysis assay Haemolysis assays were performed as described before [13]. Freshly drawn heparinised blood from healthy volunteers was centrifuged for $10 \mathrm{~min}$ at $1000 \mathrm{~g}$ at $10{ }^{\circ} \mathrm{C}$. The pellet was washed three times with $0.9 \%$ saline and diluted with saline to a $1 / 25$ packed volume of red blood cells. Triton-X100 (1\%) was used as a positive control. GS or derivative 3, 20, and VK7 were diluted in $100 \mu 1$ PBS in Ubottom 96-well plates (Greiner Bio One). Serial dilution resulted in a concentrations ranging from $62.5 \mu \mathrm{g} / \mathrm{ml}$ to $0.95 \mu \mathrm{g} / \mathrm{ml}$. DMSO (Sigma-Aldrich, Zwijndrecht, The Netherlands) was used as a solvent control. Subsequently, $50 \mu$ of the red blood cell suspension was added to the wells, and the plates were incubated at $37^{\circ} \mathrm{C}$ for $4 \mathrm{~h}$. After incubation, the plates were centrifuged at 1 , $000 \mathrm{~g}$ at $10^{\circ} \mathrm{C}$ for $4 \mathrm{~min}$, and $50 \mu \mathrm{l}$ of the supernatant of each well was dispensed into new flat-bottom 96-well plates (Greiner Bio One), and absorbance was measured at $415 \mathrm{~nm}$ in a Bio-Rad 680 spectrophotometer (Bio-Rad, Veenendaal, The Netherlands). OD values were plotted as a percentage of the positive control. Experiments were performed in triplicate.

Cytotoxicity testing Human colorectal adenocarcinoma cells (HT-29, ATCC number HTB-38, Wesel, Germany) were cultured in Dulbecco's Modified Eagle's Medium (DMEM) (Gibco, Bleiswijk, The Netherlands) with $10 \%$ FCS (Gibco) and penicillin-streptomycin (Gibco). Colourless DMEM (Gibco) with $1 \%$ FCS (Gibco) was used as assay medium. HT-29 cells were seeded at a density of $2.0 \times 10^{4}$ cells/well in a Costar flat-bottom 96-well plate (Corning, Amsterdam, The Netherlands) and incubated overnight. Serial dilutions of GS and derivatives were added and incubated for $4 \mathrm{~h}$ at $37^{\circ} \mathrm{C}$. Plates were centrifuged for $10 \mathrm{~min}$ at $1,000 \mathrm{~g}$, and the amount of LDH in the supernatants was determined (LDH release kit, Roche, Woerden, The Netherlands) following the protocol. Cytotoxicity testing was independently repeated three times.

Therapeutic indices The therapeutic index was defined as a measure of toxicity, either the $50 \%$ haemolysis or the $50 \%$ LDH release, divided by the lowest and highest MIC values seen for each strain tested. Therapeutic indices are given as a range to be compared between GS and its GS derivatives to determine improved performance.

\section{Results}

Cohort collection and characterization Five strains each of E. faecium, S. aureus, $K$. pneumoniae, A. baumannii, $P$. aeruginosa, and $E$. cloacae were collected from various wards of the Erasmus MC in 2010 and 2011 (Table 1). Extensive antibiotic resistance was observed. S. aureus and E. faecium showed resistances to penicillins, cephalosporins, lincosamides, tetracyclines, macrolides, fusidic acid, aminoglycosides, carbapenems, (fluoro)quinolones, oxazolidonones, monoxycarbolic acid, nitrofuran derivatives, rifamycins, sulfanomides, and glycopeptides. Extensive drug resistance was also observed among $K$. pneumoniae, A. baumannii, P. aeruginosa, and E. cloacae including aminoglycosides, (ureido)penicillins (in combination with beta lactamase inhibitors), fluoroquinolones, polymyxins, 
carbapenems, nitrofuran derivatives, and trimethroprim with sulfamethoxazole. Each strain showed a unique profile with resistance to several clinically used antibiotics.

MIC determination GS was active against $S$. aureus and E. faecium at 3.9-7.8 $\mu \mathrm{g} / \mathrm{ml}$ (median $3.9 \mu \mathrm{g} / \mathrm{ml}$ ) (Fig. 2). MIC values against $E$. cloacae, $P$. aeruginosa, K. pneumoniae and $A$. baumannii for GS ranged between $3.9-62.5 \mu \mathrm{g} / \mathrm{ml}$ (median $31.3 \mu \mathrm{g} / \mathrm{ml}$ ).

The beta-strand variant VK7 showed activity against S. aureus and E. faecium in the range of 3.9-15.6 $\mu \mathrm{g} / \mathrm{ml}$ (median $3.9 \mu \mathrm{g} / \mathrm{ml}$ ), comparable to parental GS. VK7 showed activity in the range of 7.8-31.2 $\mu \mathrm{g} / \mathrm{ml}$ (median $15.6 \mu \mathrm{g} / \mathrm{ml}$ ) against E. cloacae, P. aeruginosa, K. pneumoniae, and A. baumanii. The MIC values against all $P$. aeruginosa and A. baumannii strains and most $K$. pneumoniae strains are 2- to 8-fold lower for VK7 than the GS MIC values.

The $\beta$-turn variant 20 showed slightly reduced activity against $S$. aureus and E. faecium as compared to GS. MIC

\section{GS}

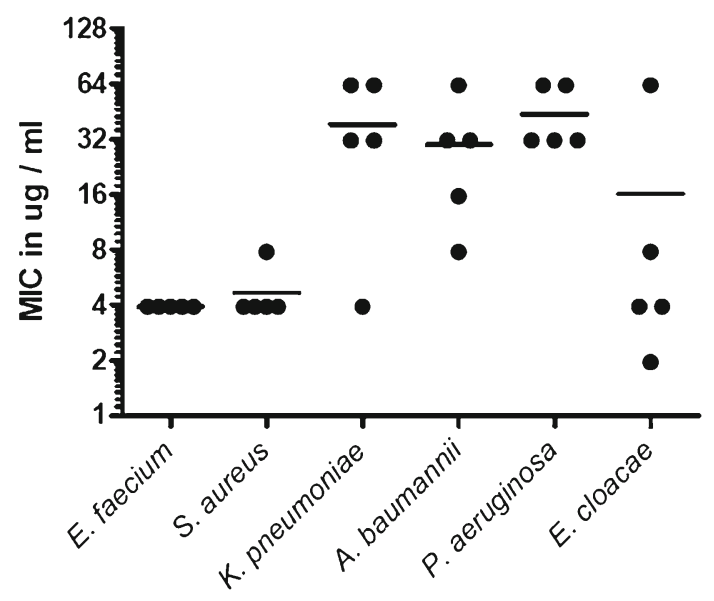

20

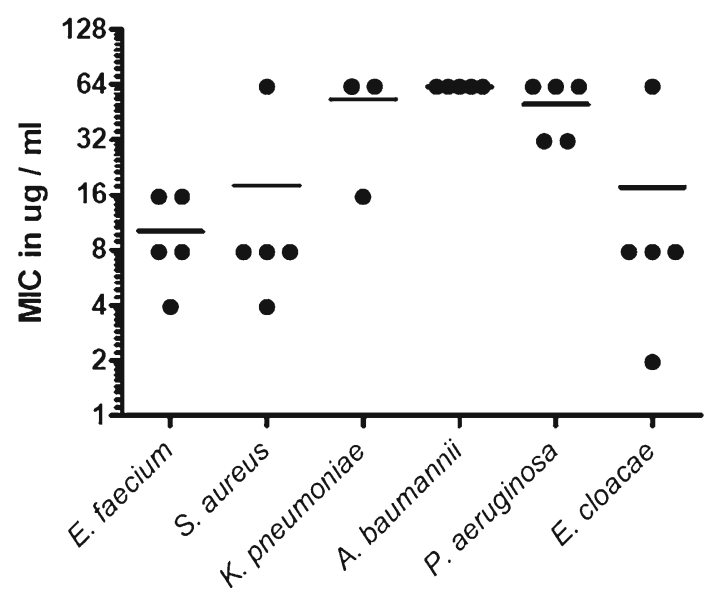

values for compound 20 were in the range of 7.8 $62.5 \mu \mathrm{g} / \mathrm{ml}$ (median $7.8 \mu \mathrm{g} / \mathrm{ml}$ ). Derivative 20 showed activity against E. cloacae, P. aeruginosa, K. pneumoniae, and A. baumannii in the range of $1.95-62.5 \mu \mathrm{g} / \mathrm{ml}$ (median $62.5 \mu \mathrm{g} / \mathrm{ml}$ ), which is slightly less than measured for the parental compound.

Derivative 3 showed activity against $S$. aureus and E. faecium in the range from $7.8-62.5 \mu \mathrm{g} / \mathrm{ml}$ (median $7.8 \mu \mathrm{g} / \mathrm{ml}$ ), which is slightly less than parental GS. Derivative 3 shows activity against the MDR Gram-negative strains E. cloacae, P. aeruginosa, K. pneumoniae, and A. baumannii in the range from 3.9-62.5 $\mu \mathrm{g} / \mathrm{ml}$ (median $31.3 \mu \mathrm{g} / \mathrm{ml}$ ), which is comparable to the parental compound.

All compounds tested were bactericidal, as sub-culturing of medium from wells without visible growth on agar media did not result in detectable growth.

Haemolysis assay and therapeutic indices Haemolysis is clearly concentration-dependant. Canonical GS showed

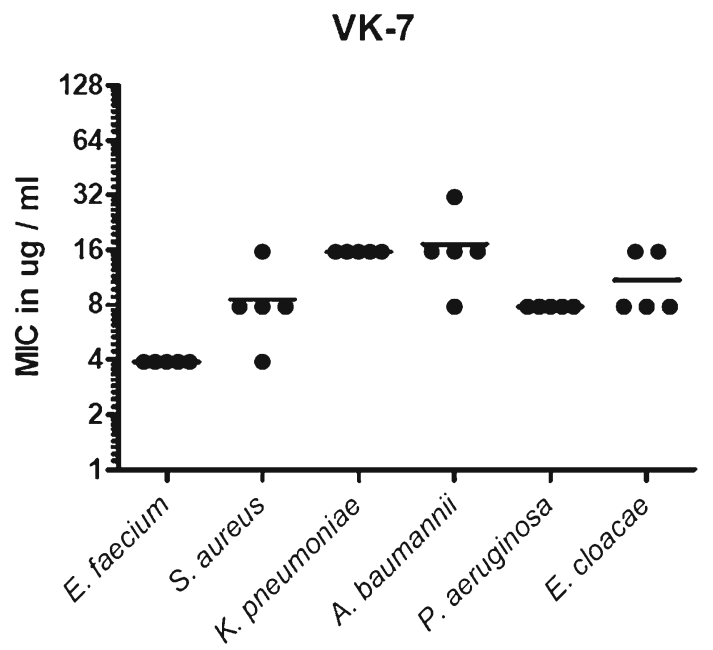

3

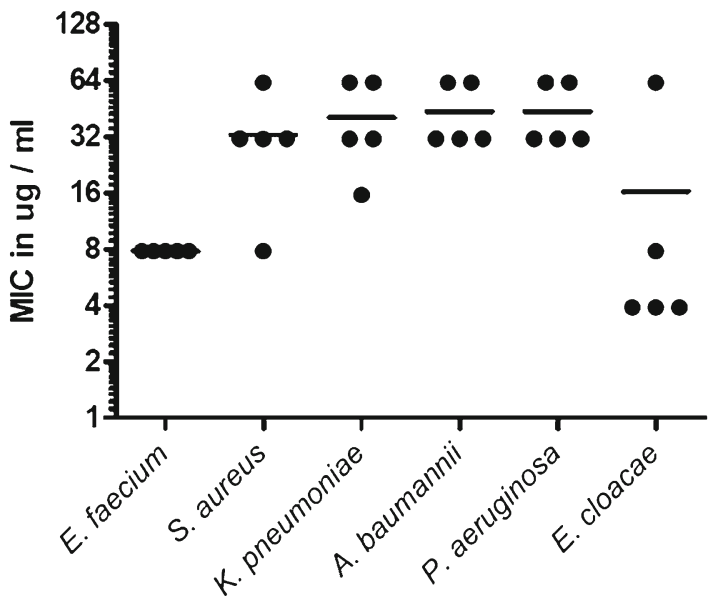

Fig. 2 MIC values for GS and its derivatives as defined for a collection 30 ESKAPE strains 
$50 \%$ haemolysis at $35.2 \mu \mathrm{g} / \mathrm{ml}$ (Fig. 3a). As the MIC values of GS varied from 3.9 to $62.5 \mu \mathrm{g} / \mathrm{ml}$, the $\mathrm{TI}_{\text {hae }}$ for GS was calculated to be between 0.56 and 18.5. Derivative 3 showed $50 \%$ haemolysis at $41.6 \mu \mathrm{g} / \mathrm{ml}$ (Fig. 3a), which is in a similar range as for the parental compound. As derivative 3 had MIC values varying from 3.9 and $62.5 \mu \mathrm{g} / \mathrm{ml}$, the $\mathrm{TI}_{\text {hae }}$ of derivative 3 was calculated to be 0.6 to 10.6 , also comparable to the parental compound. This shows that derivative 3 is not an improved antibiotic in comparison with GS. VK7 and compound 20 did not show haemolysis at $62.5 \mu \mathrm{g} / \mathrm{ml}$, which was the highest concentration tested. Hence, the exact $\mathrm{TI}_{\text {hae }}$ for compound 20 and VK7 could not be determined, but still, these derivatives are clearly less haemolytic than GS (Fig. 2).

LDH release assay and therapeutic indices The values of $50 \% \mathrm{LDH}$ release were $18.7 \mu \mathrm{g} / \mathrm{ml}$ for GS (Fig. 3b). As the
Fig. 3 Erythrocyte lysis and LDH release under the influence of GS and the derivatives a

\section{Cytotoxicity against human erythrocytes}

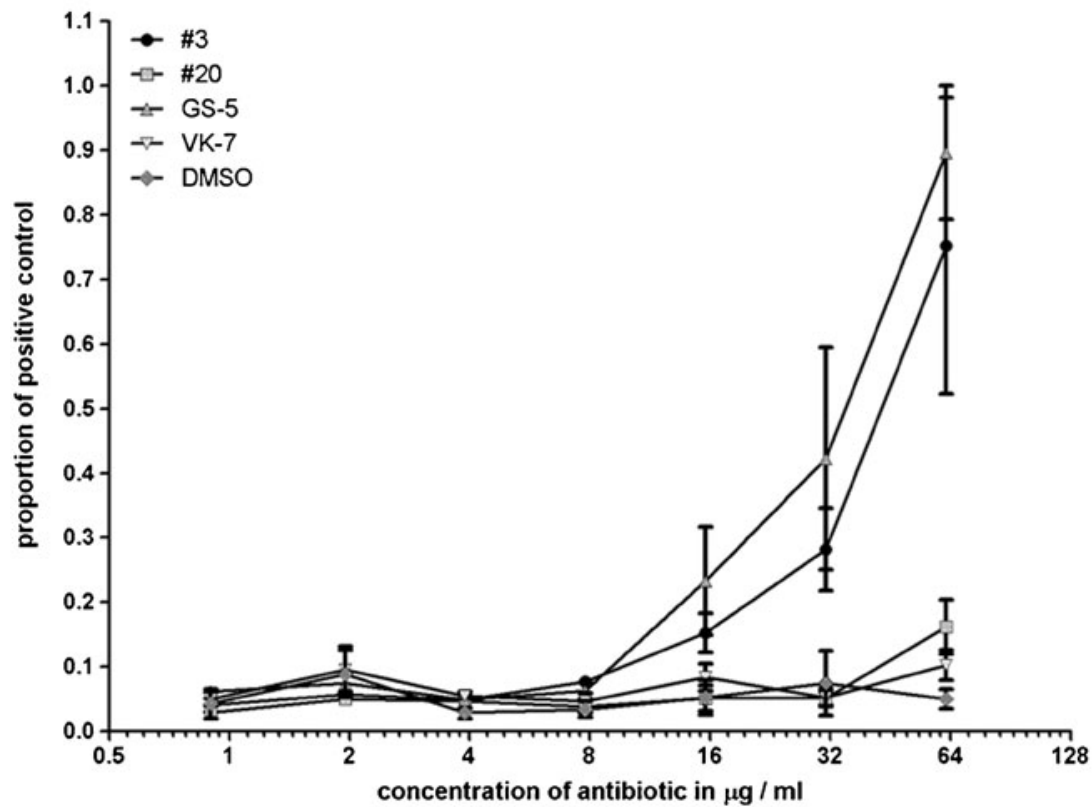

b

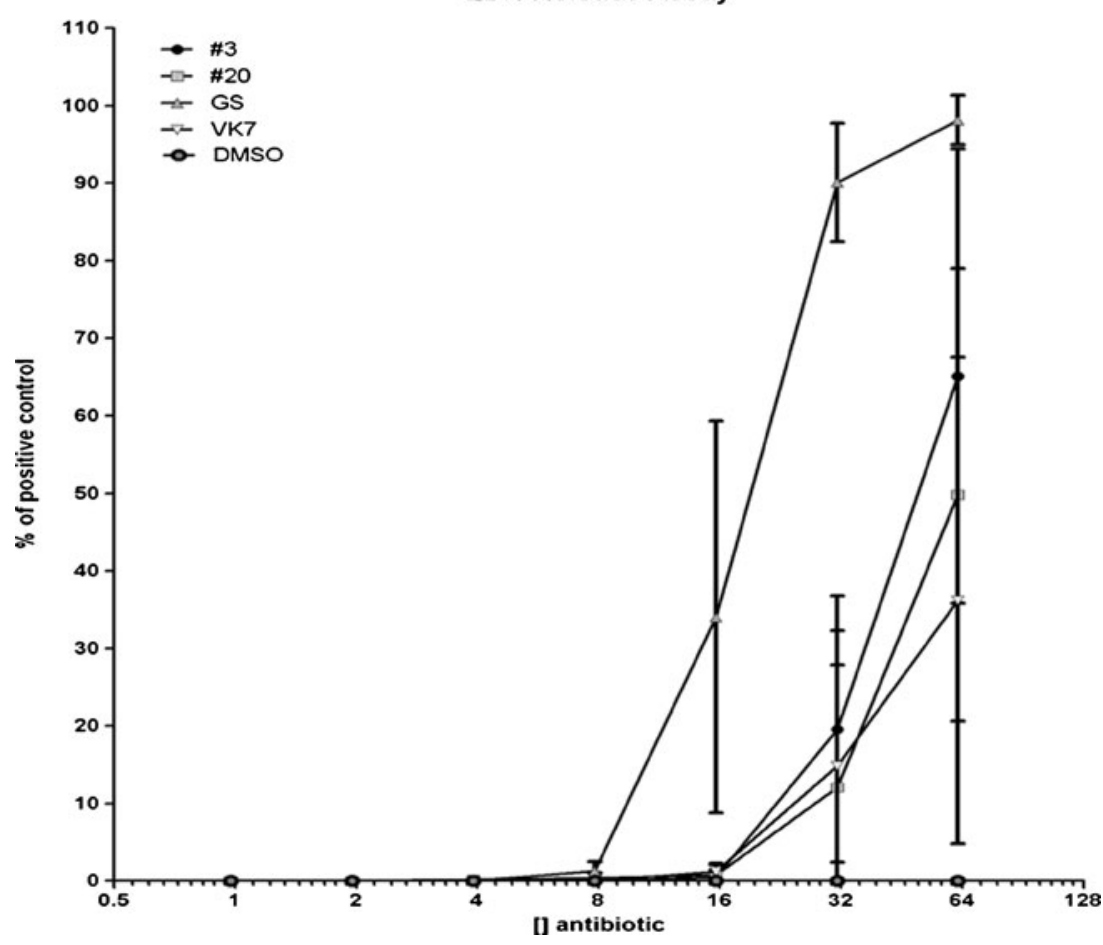


MIC values were between 3.9 and $62.5 \mu \mathrm{g} / \mathrm{ml}, \mathrm{TI}_{\mathrm{LDH}}$ was calculated to be between 0.3 and 9.6. Derivative 3 showed $50 \% \mathrm{LDH}$ release at $49.8 \mu \mathrm{g} / \mathrm{ml}$. As the MIC values were between 3.9 and $62.5 \mu \mathrm{g} / \mathrm{ml}, \mathrm{TI}_{\mathrm{LDH}}$ was calculated to be between 0.8 and 12.8, in the same range as documented for GS. Derivate 20 showed $50 \% \mathrm{LDH}$ release at $62.5 \mu \mathrm{g} / \mathrm{ml}$. As MIC values were between 1.95 and $62.5 \mu \mathrm{g} / \mathrm{ml}, \mathrm{TI}_{\mathrm{LDH}}$ was calculated to be between 1 and $32.1 \mu \mathrm{g} / \mathrm{ml}$, which shows slight improvement compared to GS. VK7 did not reach $50 \%$ LDH release at concentrations tested here. Therefore, no $\mathrm{TI}_{\mathrm{LDH}}$ could be calculated, indicating again that VK7 is less cytotoxic than GS (Table 1).

\section{Discussion}

Beta-strand modification of GS seemed to be promising for the development of new systemically applicable antibiotics. Derivative VK7 showed activity against $E$. cloacae which was equal to that of GS. Against all $P$. aeruginosa and $K$. pneumoniae and most A. baumannii there was a 2-8-fold increase in activity. The antimicrobial activity of VK7 against Gram-positive MDR pathogens such as $S$. aureus and E. faecium was similar to that of GS. In addition, we observed reduced toxicity for VK7 towards human erythrocytes and the human colorectal adenocarcinoma cell-line HT-29. The $\beta$ strand-modified VK7 has the same overall secondary structure as GS, but probably displays an elevated cationic character counterbalanced by two robust hydrophobic adamantane groups. The data indicate that $\beta$-strand modification of GS can generate interesting new antibiotics combining antimicrobial activity and lowered toxicity.

The $\beta$-turn-modified derivative 20 showed reduced toxicity compared to the parental compound, with a slight decrease in antibiotic activity compared to GS, especially when used against Gram-negatives. This $\beta$-turn-modified derivative encompasses a substituted sugar amino acid (SAA) dipeptide isoster as turn mimetic. The six-ring SAA in our lead was found to have better conformational and hydrophobic characteristics than a 4-ring (oxetane) and 5-ring (furanoid) SAA [9]. Beta-turn modification could still be promising, as at least some reduction of toxic potential is observed. Not all modifications of GS have a positive effect on antimicrobial activity and toxicity: derivative 3 shows comparable antimicrobial activity to the parental compound but a similar toxicity profile.

The synthesis of modified GS derivatives has been reported by other groups $[8,12,15,17]$. One of the key factors important in the balance between cytotoxicity and antimicrobial activity is overall hydrophobicity-hydrophilicity. Derivatives that are slightly less hydrophobic than the parental GS generally show good antimicrobial activity, while showing reduced haemolysis. Using solid- and liquid-phase organic synthesis, derivatives of GS can be obtained containing non-naturally occurring amino acids, which show reduced cytotoxicity and reduced haemolysis, while retaining antimicrobial activity.

Antimicrobial peptides may have a bright future in combating infection, as they generally do not have a single conserved target, but affect multiple bacterial processes. Modifications of the $\beta$-strand of GS in which the hydrophobic side chains have been varied are promising leads for the development of novel compounds. New derivatives of GS can possibly address the growing problem of multi-drug resistant bacteria and lead to new therapeutic compounds for systemic use, as is suggested on the basis of our current data.

Open Access This article is distributed under the terms of the Creative Commons Attribution 4.0 International License (http:// creativecommons.org/licenses/by/4.0/), which permits unrestricted use, distribution, and reproduction in any medium, provided you give appropriate credit to the original author(s) and the source, provide a link to the Creative Commons license, and indicate if changes were made.

\section{References}

1. Boucher HW, Talbot GH, Bradley JS, Edwards JE, Gilbert D, Rice LB, Scheld M, Spellberg B, Bartlett J (2009) Bad bugs, no drugs: no ESKAPE! An update from the Infectious Diseases Society of America. Clin Infect Dis 48:1-12

2. Calfee DP (2012) Methicillin-resistant Staphylococcus aureus and vancomycin-resistant enterococci, and other Gram-positives in healthcare. Curr Opin Infect Dis 25:385-394

3. Savard P, Perl TM (2012) A call for action: managing the emergence of multidrug-resistant Enterobacteriaceae in the acute care settings. Curr Opin Infect Dis 25:371-377

4. Giske CG, Monnet DL, Cars O, Carmeli Y, ReAct-Action on Antibiotic (2008) Clinical and economic impact of common multidrug-resistant gram-negative bacilli. Antimicrob Agents Chemother 52:813-821

5. Cai Y, Chai D, Wang R, Liang B, Bai N (2012) Colistin resistance of Acinetobacter baumannii: clinical reports, mechanisms and antimicrobial strategies. J Antimicrob Chemother 67:1607-1615

6. Berditsch M, Afonin S, Ulrich AS (2007) The ability of Aneurinibacillus migulanus (Bacillus brevis) to produce the antibiotic gramicidin $\mathrm{S}$ is correlated with phenotype variation. Appl Environ Microbiol 73:6620-6628

7. Dubos RJ, Hotchkiss RD (1941) The production of bactericidal substances by aerobic sporulating bacilli. J Exp Med 73:629-640

8. Kondejewski LH, Farmer SW, Wishart DS, Kay CM, Hancock RE, Hodges RS (1996) Modulation of structure and antibacterial and hemolytic activity by ring size in cyclic gramicidin $\mathrm{S}$ analogs. J Biol Chem 271:25261-25268

9. Knijnenburg AD, Spalburg E, de Neeling AJ, Mars-Groenendijk RH, Noort D, Grotenberg GM, van der Marel GA, Overkleeft HS, Overhand M (2009) Ring-extended derivatives of gramicidin S with furanoid sugar amino acids in the turn region have enhanced antimicrobial activity. Chem Med Chem 4:1976-1979

10. Herrell WE, Heilman D (1941) Experimental and clinical studies on Gramicidin. J Clin Invest 20:583-591

11. Mosges R, Baues CM, Schroder T, Sahin K (2011) Acute bacterial otitis externa: efficacy and safety of topical treatment with an antibiotic ear drop formulation in comparison to glycerol treatment. Curr Med Res Opin 27:871-878 
12. Tamaki M, Sawa K, Kikuchi S, Shindo M, Uchida Y (2006) A novel, antimicrobially active analog of gramicidin S without amphiphilic conformation. J Antibiot (Tokyo) 59:370-372

13. Knijnenburg AD, Tuin AW, Spalburg E, de Neeling AH, MarsGroenendijk RH, Noort D, Otero JM, Llamas-Saiz LM, van Raaij MJ, van der Marel GA, Overkleeft HS, Overhand M (2011) Exploring the conformational and biological versatility of betaturn-modified gramicidin $\mathrm{S}$ by using sugar amino acid homologues that vary in ring size. Chemistry 17:3995-4004

14. Kapoerchan VV, Knijnenburg AD, Niamat M, Spalburg E, de Neeling AJ, Nibbering PH, Mars-Groenendijk RH, Noort D, Otero JM, Llamas-Saiz AL, van Raaij MJ, van der Marel GA, Overkleeft HS, Overhand M (2010) An adamantyl amino acid containing gramicidin $\mathrm{S}$ analogue with broad spectrum antibacterial activity and reduced hemolytic activity. Chemistry $16: 12174$ 12181

15. Jelokhani-Niaraki M, Hodges RS, Meissner JE, Hassenstein UE, Wheaton L (2008) Interaction of gramicidin S and its aromatic amino-acid analog with phospholipid membranes. Biophys J 95: 3306-3321

16. Knijnenburg AD, Kapoerchan VV, Grotenbreg GM, Spalburg E, de Neeling AJ, Mars-Groenendijk RH, Noort D, Otero JM, Llamas-
Saiz AL, van Raaij MJ, Ravensbergen B, Nibbering PH, van der Marel GA, Overkleeft AS, Overhand M (2011) Synthesis and evaluation of strand and turn modified ring-extended gramicidin $\mathrm{S}$ derivatives. Bioorg Med Chem 19:3402-3409

17. Rambhav GN (1985) Gramicidin-S: structure-activity relationship. J Biosci 7:323-329

18. Solanas C, de la Torre BG, Fernandez-Reyes M, Santiveri CM, Jimenez MA, Rivas L, Jimenez AI, Andreu D, Cativiela C (2009) Therapeutic index of gramicidin $\mathrm{S}$ is strongly modulated by $\mathrm{D}$ phenylalanine analogues at the beta-turn. J Med Chem 52:664-674

19. Lemmens N, van Wamel W, Snijders S, Lesse AJ, Faden H, van Belkum A (2011) Genomic comparisons of USA300 Staphylococcus aureus colonizing the nose and rectum of children with skin abscesses. Microb Pathog 50:192-199

20. Clinical and Laboratory Standards Institute (2013) Breakpoint tables for interpretation of MICs and zone diameters. Version 3.0. CLSI, Wayne PA

21. Hecht DW, Onderdonk A, Aldridge KE, Roe-Carpenter D, Citron DM, Rosenblatt JE, Cox M, Webb CD, Jacobus N, Wexler HM, Jenkins SG (2004) Methods for antimicrobial susceptibility testing of anaerobic bacteria; Approved Standard vol. 24. CLSI, Wayne PA 